\title{
ФАКТОР НЕКРОЗА ОПУХОЛИ АЛЬФА ПРИ САРКОИДОЗЕ: ОТ ПАТОГЕНЕЗА К ЛЕЧЕНИЮ
}

АНАСТАСИЯ ГЕННАДИЕВНА СКРИПИНА, аспирант кафедры фтизиопульмонологии ГБОУ ВПО

«Казанский государственный медицинский университет Минздравсоцразвития PФ», e-mail: nastya_sky@mail.ru ИРИНА ЮРЬЕВНА ВИЗЕЛЬ, канд. мед. наук, ассистент кафедры фтизиопульмонологии ГБОУ ВПО

«Казанский государственный медицинский университет Минздравсоцразвития РФ», e-mail: tatpulmo@mail.ru

\begin{abstract}
Реферат. Саркоидоз - хроническое мультисистемное заболевание неизвестной природы, характеризующееся неказеифицирующейся гранулематозной инфильтрацией практически любого органа. Обычно применяемое лечение направлено на разрешение симптомов и предупреждение развития органной недостаточности. Предшествующие исследования показали важную роль фактора некроза опухоли альфа (ФНО-альфа) в воспалительном процессе, происходящем при саркоидозе. Хотя данные несравнительных исследований показали, что пентоксифиллин, метотрексат и специфические антагонисты ФНО-альфа давали хороший терапевтический эффект в некоторых случаях саркоидоза, их окончательное влияние на такие гранулематозные заболевания, как саркоидоз, остается недостаточно определенным.
\end{abstract}

Ключевые слова: саркоидоз, фактор некроза опухоли альфа, терапия.

\section{THE TUMOR NECROSIS FACTOR-ALPHA IN SARCOIDOSIS: FROM PATHOGENESIS TO TREATMENT}

\section{A.G. SKRYPKINA, I.YU. VIZEL}

\begin{abstract}
Sarcoidosis is a chronic multisystem disease of unknown etiology, characterized by noncaseating granulomatous infiltration of virtually any organ system. Treatment is often undertaken in an attempt to resolve symptoms or prevent progression to organ failure. Previous studies have suggested a prominent role for tumor necrosis factor-alpha (TNF-alpha) in the inflammatory process seen in sarcoidosis. Although data from noncomparative trials suggest that pentoxifilline, methotrexate and specific TNF antagonists have good therapeutic effects in some cases of sarcoidosis, their target effects in a granulomatous disease such as sarcoidosis are less consistent.

Key words: sarcoidosis, tumor necrosis factor alfa, treatment.
\end{abstract}

Саркоидоз - мультисистемное гранулематозное заболевание неизвестной этиологии, характеризующееся накоплением во многих органах активированных Т-лимфоцитов (CD4+) и макрофрагов и образованием в них эпителиоидно-клеточных неказеифицирующихся гранулем, нарушением нормальной архитектуры пораженного органа или органов, распространенность которого в последние годы растет [1].

В течение прошедших 30 лет понимание саркоидоза неоднократно менялось, его связывали с инфекциями (в МКБ-9), с иммунодефицитом, а одна из последних трактовок патогенеза этого гранулематоза - генетически детерминированная гиперактивность иммунной системы, ведущая к гранулематозному воспалению, вызванному неизвестным антигеном (триггером) и опосредованному механизмами клеточного иммунитета [26]. Специалисты из разных стран приходят к мнению о том, что «стандартное» лечение саркоидоза, основанное на различных режимах глюкокортикостероидной терапии, не лишено серьезных побочных реакций и не гарантирует серьезных обострений и рецидивов. Одним из поисковых направлений является терапия биологически активными веществами. Цитокины и хемокины являются важными компонентами в патофизиологии саркоидоза. В течение последней декады XX в. было показано, что именно эти медиаторы приводят к альвеолиту, образованию гранулем и тканевому повреждению. Эти сведения стали толчком к изучению потенциальных антагонистов цитокинов, которые должны контролировать активность воспалительных заболеваний.
Доказано, что в местах развития патологического процесса при саркоидозе имеет место высокий уровень иммунологической активности макрофагов и лимфоцитов: активно накапливаются Т-хелперы в жидкости бронхоальвеолярного лаважа (БАЛ), а мононуклеары продуцируют повышенное количество интерлейкинов 1 и 2, фрактора некроза опухоли альфа (ФНО-альфа). При этом ФНО-альфа считается ключевым цитокином, участвующим в формировании гранулемы при саркоидозе [2]. Повышенная экспрессия І-каппа-В-альфа жидкости БАЛ больных саркоидозом показала, что продукция ФНО-альфа и интерлейкина-6 (ИЛ-6) альвеолярными макрофагами и продукция интерферона-гамма Т-клетками зависели от универсального фактора транскрипции NF-kappaB [4]. Китайские исследователи отмечали, что уровень ФНО-альфа при саркоидозе в жидкости БАЛ был достоверно выше, чем у здоровых, и выше, чем в сыворотке крови. Уровень ФНО-альфа в жидкости БАЛ у больных саркоидозом положительно коррелировал с процентом лимфоцитов, что позволило им расценить этот цитокин как маркер активности этого заболевания [9]. Отечественные авторы на конгрессе по саркоидозу в Стокгольме также констатировали корреляцию между клинической активностью саркоидоза и уровнем ИЛ-1, ИЛ-4, ИЛ-6 и ФНО-альфа сыворотки крови [30].

Известно, что адгезионные молекулы-1 (Intracellular Adhesion Molecule-1 или ICAM-1) опосредуют межклеточную адгезию и играют важную роль в развитии местного воспаления. Недавно японскими учеными было показано, что при легочном саркоидозе экспрес- 
сия ICAM-1 на поверхности макрофрагов повышена, и образование воспалительных гранулем связано с агрегацией макрофагов. Проведенное исследование показало, что за значительно повышенную в сравнении со здоровыми экспрессию ICAM-1 на альвеолярных макрофрагах больных саркоидозом ответственны ФНОальфа и другие цитокины [29].

Вырабатываемый альвеолярными макрофагами ФНО-альфа играет центральную роль в патогенезе саркоидоза и экзогенного аллергического альвеолита (ЭАА). Эффрект ФНО-альфа опосредуется мембранными рецепторами mФHO-R-I и mФHOR-II и может быть заблокирован растворимыми ФНО-альфа рецепторами S-ФHO-R-I и sФHO-R-II. Исследователи из Эссена измерили продукцию двух s-ФНО-R и ФНО-альфа в супернатанте культуры альвеолярных макрофагов, полученных от 10 больных активным саркоидозом, 13 больных ЭАА и 9 контрольных субъектов. В сравнении со здоровыми спонтанная и стимулированная липополисахаридом продукция sФHO-R-I, sФHO-R-II и ФНО-альфа достоверно возрастала у больных саркоидозом и ЭАА. Концентрация обеих sФHO-R, но особенно - sФHO-R-II, была тесно связана с таковой для ФНО-альфа. При индукции липополисахаридом sФHO-R-I увеличивался в 1,5 раза, sФHO-R-II в 4 раза, и, как минимум, в 25 раз - ФНО-альфра во всех исследованных популяциях. Авторы сделали вывод о том, что sФHO-R-I и sФHO-R-II могут быть вовлечены в патогенез саркоидоза и ЭАА, вероятно, как фракторы, противодействующие ФНО-альфа [11].

С тех пор как ФНО-альфа стал известен как медиатор образования гранулем, и в активную фазу саркоидоза стали отмечать повышенный уровень ФНО-альфа, появился интерес к научным исследованиям корреляции генетических фракторов, влияющих на активность ФНО-альфа. Предшествующие исследования показали, что на продукцию ФНО-альфа влияет биаллельный полиморфизм генов ФНО-альфа (-308, ФНО-альфа) и ФНО-бета (intron 1, ФНОВ) [23].

Таким образом, работы иммунологов и генетиков показывают, что патогенез и течение болезни связаны скорее с гаплотипом, чем с одним специфичным геном, определяющим вероятность высокого уровня ФНОальфа в крови и в органах, пораженных саркоидозом. Коль скоро эти работы свидетельствовали о ведущей роли цитокина ФНО-альфа в патогенезе саркоидоза, то логично было бы предположить, что лечебные воздействия, направленные на снижение уровня ФНОальфа, способны благоприятно повлиять на состояние больных этой нозологией, особенно рефрактерной к обычному лечению.

Блокада ФНО-альфа стала важным звеном иммуномодулирующей терапии, особенно у пациентов, не восприимчивых к обычной иммуносупрессии, но ответ на такое воздействие может быть непредсказуемым. Понимание всей сложности обмена ФНО-альфа в человеческом организме может стать ключом к прогнозированию как лечебного, так и нежелательного действия. Накопление ФНО-альфа отчасти ограничено его расщеплением, частично отрегулировано расщеплением ФНО-альфа преобразовывающим ферментом TACE; он также может быть расщеплен протеиназой-3 (PR-3). Протеиназа-3 вносит больший вклад в расщепление ФНО-альфа при заболевании с преобладанием нейтрофильного компонента, типичным для обычной интерстициальной пневмонии, по сравнению с саркоидозом, где преобладают лимфоциты [37].

В пользу того, что подавление ФНО-альфа целесообразно именно на ранних стадиях заболевания, свидетельствует тот фракт, что альвеолярные макрофраги являются главным клеточным источником ФНО-альфа в начальной фразе саркоидоза. Авторы отмечали, что у этих больных скопление альвеолярных макрофагов может быть событием, предшествующим образованию гранулемы [5].

Число работ, свидетельствующих об эффрективности средств, подавляющих ФНО-альфа, таких как пентоксифиллин, талидомид, этанерцепт и инфликсимаб, в последние годы растет. Поскольку ФНО-альфа вырабатывают макрофраги и другие клетки, он участвует в гранулематозном воспалении, новой поисковой стратегией в лечении саркоидоза считается противодействие активности ФНО-альфа.

Среди широко известных в клинике внутренних болезней препаратов влияние на уровень ФНО-альфа оказывает пентоксифиллин - сосудорасширяющее, ангиопротективное, антиагрегационное, улучшающее микроциркуляцию средство из группы пуринов. В современной классификации иммунных препаратов пентоксифиллин относят к средствам антицитокиновой терапии.

При применении пентоксифиллина как нормализующего реологию крови средства были отмечены его противовоспалительные свойства, дальнейшее изучение которых показало его перспективность как иммуномодулятора для лечения пациентов, подвергающихся операциям на сердце [14]. Ранее противовоспалительные свойства пентоксифиллина были использованы при лечении пациентов с реакцией отторжения трансплантата [7]

Китайские исследователи в экспериментах на культуре клеток альвеолярных макрофрагов, взятых у 14 больных активным саркоидозом, показали, что пентоксифиллин вызывает достоверную дозозависимую супрессию выброса ФНО-альфа альвеолярными макрофагами больных саркоидозом, подавляет выработку стимулированных липополисахаридами цитокинов, кроме рецептора sФHO-R-1. Авторы сделали вывод о том, что пентоксифиллин может быть препаратом в лечении саркоидоза, хотя отметили необходимость его дальнейших клинических испытаний [16].

Можно встретить весьма обнадеживающие работы в клинике саркоидоза. Пентоксифиллин один или в сочетании с малыми дозами кортикостероидов позволял достичь значительного улучшения респираторной функции пациентов с легочным саркоидозом [13].

Белорусские фртизиопульмонологи исследовали способность пентоксифиллина угнетать спонтанную секрецию ФНО-альфа в индуцированной мокроте и улучшать результаты лечения саркоидоза, отметив эфффективность применения пентоксифиллина у вновь выявленных пациентов [35].

Исследователи из Москвы проанализировали эффекты пентоксифиллина у пациентов с легочной гипертензией, связанной с саркоидозом и пришли к выводу, что долгосрочная терапия пентоксифиллином (вазонитом) может быть рекомендована как эфффективная у пациентов с легочной гипертонией из-за саркоидоза [28].

В исследованиях сотрудников Казанского медицинского университета было показано, что 3-месячный курс 
лечения пентоксифиллином в дозе 200 мг 3 раза в день (600 мг/сут) приводил к улучшение общего состояния пациентов, достоверному улучшению рентгенологической картины, достоверному увеличению жизненной емкости легких, также значимому увеличению ОФВ, и ПСВ [22]. Последующее изучение 70 больных показало, что пентоксифиллин в низкой дозе (600 мг/сут) может быть препаратом выбора в сочетании с альфатокоферолом при вновь выявленном саркоидозе I-III рентгенологической стадии. Вероятность клинического эффректа сочетания пентоксифиллина с витамином E была снижена при хронически текущем саркоидозе, а также у больных, получавших ранее системные ГКС или противотуберкулезные препараты [3].

Интересна оценка пентоксифиллина в качестве средства, снижающего дозу системных кортикостероидов. Комбинация системных кортикостероидов с пентоксифриллином может быть полезна для лечения больных активным саркоидозом, не отвечающим на лечение высокими дозами системных кортикостероидов и может обладать стероидснижающим эфффектом при лечении активного саркоидоза, тем самым уменьшая тяжелые побочные эффекты длительной стероидной терапии.

Метотрексат - противоопухолевое, цитостатическое средство группы антиметаболитов, обладающее имунносупрессивной активностью отчасти вследствие способности подавлять деление лимфоцитов. Имеются исследования, в которых показана эффрективность орального метотрексата в лечении больных с мультисистемными заболеваниями (ревматоидный артрит, гранулематоз Вегенера, различные аутоиммунные болезни и саркоидоз) [32].

Авторы из США в ходе проведения нерандомизированного интервенционного исследования в течение двух лет пришли к заключению о том, что метотрексат - хорошо переносимый терапевтический агент, существенно сокращающий дозу гормонов и эффеективный для лечения хронического симптоматического саркоидоза [20]. Теми же авторами дано заключение, что метотрексат может сокращать дозу гормонов и при остром саркоидозе. Метотрексат подавляет функции различных клеток, модулирует выработку цитокинов и пролиферацию фибробластов, проявляя тем самым свое противовоспалительное действие. Эффективные дозы метотрексата при саркоидозе приводят к существенным изменениям в лимфоцитах и макрофрагах бронхоальвеолярного лаважа.

Успешно применяется метотрексат при саркоидозе в педиатрической практике. Назначенный перорально в низких дозах он был эффективен, безопасен и позволил снизить дозу гормонов у некоторых пациентов. Французские ревматологи наблюдали 5 пациентов с доказанным биопсией саркоидозом и наличием упорной формы заболевания. Авторы сделали вывод, что метотрексат эфффективный, безопасный терапевтический агент, позволяющий снизить дозу гормонов для лечения хронических скелетно-мышечных проявлений саркоидоза [19].

Метотрексат применяется при лечении кожных форм саркоидоза. Он рекомендован главным образом пациентам, которые не ответили на предшествующее лечение местными кортикостероидами или противомалярийными препаратами [21].

Эффрективность малых доз метотрексата была продемонстрирована при саркоидозном поражении глаз. Американские офтальмологи определяли безопас- ность и эффективность низких доз метотрексата (MTX) при саркоидозассоциированном панувеите [10].

Другое сообщение также показало эффрективность метотрексата при лечении саркоидозной оптической невропатии (SAON). Пероральный MTX уменьшал потребность в кортикостероидах у трех пациентов с SAON, и все они продемонстрировали устойчивое улучшение зрительной функции [38].

Комбинированная иммуносупрессивная терапия рассматривается как потенциальное лечение невосприимчивого саркоидоза костного мозга [18].

Инфликсимаб. Благодаря интенсивным разработкам ревматологов в практику вошел препарат инфллксимаб (infliximab) - химерические человеческомышиные моноклональные антитела против человеческого ФНО-альфа. Он был одобрен FDA для лечения болезни Крона, ревматоидного артрита. Публикации последних лет свидетельствуют о его эффективности при саркоидозе.

Американские ревматологи целенаправленно изучили потенциальную роль нейтрализации фактора некроза опухоли при ревматологических заболеваниях, отличных от ревматоидного артрита. Они проанализировали публикации в американских и европейских журналах по безопасному и эффрективному подавлению ФНО-альфа при лечении ревматологических заболеваний, отличных от ревматоидного артрита. Клинические испытания, открытые исследования и описания случаев являются многообещающими как при монотерапии, так и в комбинации с другими протоколами лечения этих состояний. В рандомизированном, двойном слепом, плацебоконтролируемом испытании этанерцепта и в открытом изучении инфликсимаба при псориатическом артрите, а также при анкилозирующем спондиллите эти 2 ингибитора ФНО привели к ответной реакции примерно в $80 \%$ и $90 \%$. Был сделан вывод о том, что ингибиторы ФНОальфа могут быть эффективны в лечении болезни Бехчета, гранулематоза Вегенера и саркоидоза, что нейтрализация ФНО-альфа может играть важную роль в лечении ревматологических заболеваний, отличных от ревматидного артрита [32].

На Европейском респираторном конгрессе в Мюнхене были представлены результаты межнационального рандомизированного клинического испытания инфрликсимаба при хроническом саркоидозе легких в течение 24 нед, в котором было отмечено улучшение рентгенологической картины и ФЖЕЛ [8].

Инфрликсимаб приводил к клиническому улучшению и уменьшению потребности в кортикостероидах в исследованиях на небольших группах больных саркоидозом. Исследователи предупреждали, что инфликсимаб может приводить к реактивации туберкулеза, что по ошибке может быть расценено как ухудшение течения саркоидоза, и он должен с осторожностью применяться у больных из групп риска [6].

Американские ревматологи изучили эфффективность лечения ингибитором ФНО-альфа саркоидоза, рефрактерного к общепринятому лечению. Было обследовано 5 больных (2 мужчины и 3 женщины), которых лечили инфликсимабом. Во всех случаях лечение инфрлисимабом привело к достоверному улучшению без серьезных побочных реакций [24].

Неврологи из Нью-Йорка (США) наблюдали 35летнюю женщину с головной болью, хроническим снижением зрения, отеком зрительного соска и атро- 
фрией зрительного нерва, характерными для внутричерепной гипертензии. МРТ выявила двусторонний отек фронтальных отделов мозга. Снижение зрения продолжалось, несмотря на общепринятое лечение. Применение инфликсимаба сохранило зрительную функцию ее правого глаза. Авторы отметили, что понимание множественности этиологических механизмов отека зрительного диска при саркоидозе способствуют оптимизации лечения [34].

В Ганновере был описан больной с тяжелым саркоидозом, поражавшим легкие и печень. Различные режимы лечения, включавшие азатиоприн, метотрексат, циклофосфрамид и пентоксифиллин, не дали эффекта, была назначена «терапия спасения» инфликсимабом. Была получена положительная динамика суставного, легочного и печеночного процессов, была снижена доза системных стероидов. По мнению авторов, это было первое сообщение об успешном лечении инфрликсимабом мультиорганного саркоидоза, резистентного к другим видам лечения [16]. В том же году был описан случай успешного лечения инфликсимабом распространенного и прогрессирующего саркоидоза кожи [27].

Этанерцепт (Etanercept) является димерным белковым соединением, которое специфически связывает ФНО-альфа, делая его биологически не активным. Ревматологи из Калифорнии отмечали хороший эфффект этанерцепта при саркоидозе с поражением суставов и кожи [11]. При метаанализе было отмечено, что в рандомизированном, двойном слепом, плацебоконтролируемом испытании этанерцепта при псориатическом артрите этот ингибитор ФНО-альфа привел к ответной реакции примерно в $80 \%$ случаев [32].

В то же время есть и другие мнения. Ученые из клиники Мейо (Рочестер, США) провели изучение этанерцепта при лечении прогрессирующего легочного саркоидоза II и III стадии в проспективном, открытом исследовании (фаза 2). Этанерцепт назначали по 25 мг подкожно 2 раза в нед и оценивали ФВД, рентгенограммы ОГК, степень одышки, уровень ФНО-альфа в сыворотке крови и жидкости БАЛ. Исследование было прекращено досрочно ввиду недостаточной эфрфективности препарата после того, как лечение прошли 17 пациентов. Ни в одном случае ни абсолютный уровень ФНО-альфра, ни активность ФНО-альфа в сыворотке крови, жидкости БАЛ или в альвеолярных макрофагах не изменились. Был сделан вывод о том, что этанерцепт недостаточно эффрективен при саркоидозе, что проведение его изучения в большом многоцентровом исследовании в сравнении со стероидами нецелесообразно [12].

Есть и более тревожные сообщения. Американские ревматологи наблюдали 7-летнего мальчика, у которого первоначально диагностировали полиартикулярный ювенильный идиопатический артрит, на раннем этапе лечения этанерцептом стали очевидны клинические и лабораторные признаки возникшего саркоидоза: у него развился панувеит, папулярная сыпь на коже и повышение уровня АПФ. В печени были обнаружены неказеифицирующиеся гранулемы. После прекращения лечения этанерцептом и применения системных кортикостероидов увеит прекратился [15]. В более поздней работе описано еще 2 случая индукции развития саркоидоза этанерцептом и 1 случай - инфликсимабом [36]

Заключение. Представленный анализ литературы свидетельствует о том, что наметилось новое перспек- тивное направление в лечении саркоидоза, основанное на влиянии на уровень ФНО-альфа. Однако при практическом применении таких средств, как пентоксифиллин, метотрексат, инфликсимаб, этанерцепт, пока остаются открытыми вопросы по дозированию, длительности и безопасности их применения. С одной стороны, патофизиологическая составляющая эффектов ФНО-альфа свидетельствует о целесообразности применения этих препаратов на ранних стадиях гранулемообразования, тогда как многие исследования проведены на больных, получавших без успеха препараты разных классов, что могло модифицировать эфффект анти-ФНО-терапии.

По данным на август 2011 г., в доступной базе PubMed MEDLINE поиск по ключевым словам «sarcoidosis» и «TNF» дает 263 статьи и еще 4491 статью о роли гена, ответственного за ФНО-альфа. Интерес к этому направлению исследований велик, и можно надеяться, что в ближайшее время будут получены новые данные, которые позволят расширить применение этих препаратов в лечении саркоидоза

\section{ЛИТЕРАТУРА}

1. Визель, А.А. Саркоидоз: обзор работ последних лет А.А. Визель // Пульмонология. - 2009. — № 1. - С.83.

2. Гергерт, В.Я. Активность иммунокомпетентных клеток и макрофагов при саркоидозе легких (в сравнении с туберкулезом) / В.Я. Гергерт, З.П. Абрамова, Г.А. Космиади // Пробл. туберкулеза. - 1996. - № 1. - С.35-38.

3. Оценка эффективности малых доз пентоксифиллина в сочетании с токоферола ацетатом при внутригрудном саркоидозе / А.А. Визель, Е.А. Визель, Г.Р. Насретдинова [и др.] // Пульмонология. - 2005. - № 1. - С.24-28.

4. Alveolar macrophages and T cells from sarcoid, but not normal lung, are permissive to adenovirus infection and allow analysis of nf-kappab-dependent signaling pathways / M. Conron, J. Bondeson, P. Pantelidis [et al.] // Amer. J. Respir. Cell. Mol. Biol. - 2001. - Vol. 25, № 2. - P.141-149.

5. Alveolar macrophages are the main source for tumour necrosis factor-alpha in patients with sarcoidosis / $\mathrm{H}$. Fehrenbach, G. Zissel, T. Goldmann [et al.] // Eur. Respir. J. — 2003. Vol. 21, № 3. - P.421-428.

6. Baughman, R.P. Tumour necrosis factor in sarcoidosis and its potential for targeted therapy / R.P. Baughman, M. Iannuzzi // BioDrugs. - 2003. - Vol. 17, № 6. - P.425-431.

7. Boggess, K.A. Management and outcome of pregnant women with interstitial and restrictive lung disease / K.A. Boggess, T.R. Easterling, G. Raghu // Amer. J. Obstet. Gynecol. 1995. - Vol. 173, № 4. - P.1007-1114.

8. Changes of chest roentgenogram during a double blind randomized trial of infliximab for chronic pulmonary sarcoidosis / M. Drent, U. Costabel, R. Shiphley [et al.] // Europ. Resp. J. - 2006. - Vol. 28, suppl. 50. - P.731.

9. Detection of TNF-alfa and NCF in the serum and BALF of patients with sarcoidosis and evaluate their clinical significance / Z. Li, W. Chen, X. Hou [et al.] // Zhonghua Jie He He Hu Xi Za Zhi. - 1999. - Vol. 22, № 1. - P.37-39.

10. Dev, S. Methotrexate treatment for sarcoid-associated panuveitis / S. Dev, R.M. McCallum, G.J. Jaffe // Ophthalmology. - 1999. - Vol. 106, № 1. - P.8-111.

11. Etanercept ameliorates sarcoidosis arthritis and skin disease/ D. Khanna, M.R. Liebling, J.S. Louie [et al.] // J. Rheumatol. 2003. - Vol. 30, № 8. - P.1864-1867

12. Etanercept for the treatment of stage II and III progressive pulmonary sarcoidosis / J.P. Utz, A.H. Limper, S. Kalra [et al.] // Chest. - 2003. — Vol. 124, № 1. - P.177-185.

13. Fazzi, $P$. Pharmacotherapeutic management of pulmonary sarcoidosis / P. Fazzi // Am. J. Respir. Med. - 2003. - Vol. 2, № 4. - P.311-320.

14. Groesdonk, H.V. Anti-inflammatory effects of pentoxifylline: Importance in cardiac surgery / H.V. Groesdonk, M. Herin- 
glake, H. Heinze // Anaesthesist. - 2009. - Vol. 58, № 11. - P.43-1136.

15. Hashkes, P.J. Sarcoid-related uveitis occurring during etanercept therapy / P.J. Hashkes, I. Shajrawi // Clin. Exp. Rheumatol. — 2003. — Vol. 21, № 5. - P.645-646.

16. Inhibition of cytokine release from alveolar macrophages in pulmonary sarcoidosis by pentoxifylline / Z.H. Tong, H.P. Dai, B.M. Chen [et al.] // Zhonghua Jie He He Hu Xi Za Zhi. 2003. — Vol. 26, № 7. — P.5-8.

17. Interferon-Alpha-associated sarcoidosis responsive to infliximab therapy / Y. Menon, E. Cucurull, E. Reisin, L.R. Espinoza // Am. J. Med. Sci. - 2004. - Vol. 328, № 3. - P.173-175.

18. Kalajian, A.H. Sarcoidal anemia and leukopenia treated with methotrexate and mycophenolate mofetil / A.H. Kalajian, J.R. Van Meter, J.P. Callen // Arch. Dermatol. - 2009. Vol. 145, № 8. - P.9-905.

19. Low-dose methotrexate: an effective corticosteroid-sparing agent in the musculoskeletal manifestations of sarcoidosis / O. Kaye, E. Palazzo, M. Grossin [et al.] // Br. J. Rheumatol. 1995. - Vol. 34, № 7. - P.4-642.

20. Lower, E.E. Prolonged use of methotrexate for sarcoidosis / E.E. Lower, R.P. Baughman // Arch Intern Med. - 1995. Vol. 155, № 8. - P.51-846.

21. Methotrexate for the treatment of patients with chronic cutaneous sarcoidosis: 4 cases / A. Gary, A.B. Modeste, C. Richard [et al.] // Ann. Dermatol. Venereol. - 2005. Vol. 132, № 8/9. - P.62-659.

22. Pentoxifylline in treatment of pulmonary sarcoidosis G.R. Nasretdinova, A.A. Vizel, M.E. Gouryleva, N.B. Amirov // Europ. Resp. J. - 2002. - Vol. 20, suppl. 38. - P.4332749.

23. Polymorphisms at position-308 in the promoter region of the TNF-alpha and in the first intron of the TNF-beta genes and spontaneous and lipopolysaccharide-induced tnf-alpha release in sarcoidosis / A. Somoskovi, G. Zissel, U. Seitzer [et al.] // Cytokine. - 1999. - Vol. 11, № 11. - P.882-887.

24. Pritchard, $C$. Tumour necrosis factor alpha inhibitor treatment for sarcoidosis refractory to conventional treatments: a report of five patients / C. Pritchard, K. Nadarajah // Ann. Rheum. Dis. - 2004. - Vol. 63, № 3. - P.318-20.

25. Production of soluble tumor necrosis factor receptors and tumor necrosis factor-alpha by alveolar macrophages in sarcoidosis and extrinsic allergic alveolitis / H. Dai, J. Guzman, B. Chen, U. Costabel // Chest. — 2005. — Vol. 127, № 1. P.251-256.

26. Progressive and refractory sarcoidosis: observations on the antibody (infliximab) as a theraputic use of anti-tumor nectrosis factor agent / Y.P. Kataria, M. Judson, O.P. Sharma [et al.] // Abstract book of 7th WASOG Congress in Stockholm, June 16-19, Section OP. - 2002. — № 8.

27. Progressive cutaneous sarcoidosis responding to anti-tumor necrosis factor-alpha therapy / L. Mallbris, A. Ljungberg, M.A. Hedblad [et al.] // J. Am. Acad. Dermatol. - 2003. Vol. 48, № 2. - P.290-293.

28. Pulmonary hypertension associated with sarcoidosis and experience of treatment with pentoxifylline (Vasonite) / E.N. Popova, S.B. Bolevich, V.V. Fomin [et al.] // Europ. Resp. J. -2006 . - Vol. 28, suppl. 50. - P.2491.

29. Role of ICAM-1 in the aggregation and adhesion of human alveolar macrophages in response to TNF-alpha and INFgamma / M. Sasaki, Y. Namioka, T. Ito [et al.] // Mediators Inflamm. — 2001. —Vol. 10, № 6. - P.309-313.

30. Sarcoidosis activity: the approaches comparison / S. Borissov, E. Kupavtzeva, E. Bogorodskaia [et al.] // Abstract book of 7th WASOG Congress in Stockholm, June 16-19. - Stockholm, 2002. — № 12.

31. Scheinfeld, $N$. Off-label uses and side effects of infliximab / N. Scheinfeld // J. Drugs Dermatol. - 2004. - Vol. 3, № 3. - P.273-284.

32. Stokes, D. G. Potential of tumor necrosis factor neutralization strategies in rheumatologic disorders other than rheumatoid arthritis / D.G. Stokes, J.M. Kremer // Semin. Arthritis Rheum. - 2003. - Vol. 33, № 1. - P.1-18.

33. Successful tumor necrosis factor alpha blockade treatment in therapy-resistant sarcoidosis / K.U. Ulbricht, M. Stoll, J. Bierwirth [et al.] // Arthritis Rheum. - 2003. - Vol. 48, № 12. - P.3542-3543.

34. The pathogenesis and treatment of optic disc swelling in neurosarcoidosis: a unique therapeutic response to infliximab / J.M. Katz, M.K. Bruno, J.M. Winterkorn, N. Nealon // Arch. Neurol. - 2003. - Vol. 60, № 3. - P.426-430.

35. TNF-a release suppression by pentoxifylline in sarcoidosis / H.L. Baradzina, I.L. Katovich, A.D. Tahanovich [et al.] // Europ. Resp. J. - 2003. - Vol. 22, suppl. 40. - P.105-731.

36. Tumor necrosis factor-alpha antagonist-induced sarcoidosis / R.R. Clementine, J. Lyman, J. Zakem, [et al.] // J. Clin. Rheumatol. - 2010. — Vol. 16, № 6. - P.274-279.

37. Tumour necrosis factor-alpha processing in interstitial lung disease: a potential role for exogenous proteinase-3 / L. Armstrong, S.I. Godinho, K.M. Uppington [et al.] // Clin. Exp. Immunol. - 2009. - Vol. 156, № 2. - P.43336.

38. Use of methotrexate in sarcoid-associated optic neuropathy / H.A. Maust, R. Foroozan, R.C. Sergott [et al.] // Ophthalmology. — 2003. — Vol. 110, № 3. - P.63-559.

\title{
ТАБАЧНАЯ ЭПИДЕМИЯ:
}

\section{ФАРМАКОЛОГИЧЕСКИЕ ВОЗМОЖНОСТИ БОРЬБЫ}

НАИЛЬ БАГАУВИЧ АМИРОВ, докт. мед. Наук, профессор кафедры общей врачебной практики ГБОУ ВПО «Казанский государственный медицинский университет Минздравсоцразвития РФ", тел. +7-9053130111, e-mail: namirov@mail.ru TАТЬЯНА ИЛЬИнИЧнА АНДРЕЕВА, канд. мед. наук, доцент кафедры школа здравоохранения Национального университета «Киево-Могилянская академия», Киев, Украина, e-mail: tatianandreeva@yandex.ru

Реферат. В работе показаны последствия распространения никотиновой зависимости. Описаны немедикаментозные и медикаментозные методы борьбы с табачной эпидемией.

Ключевые слова: табачная эпидемия, методы фрармакотерапии.

\section{THE TOBACCO EPIDEMIC: PHARMACOLOGICAL CONTROL FEATURES}

\author{
N.B. AMIROV, T.I. ANDREYEVA
}

Abstract. This article demonstrates the consequences of prevalence of nicotine addiction. Describes non pharmacotherapy and pharmacotherapy methods of struggle with tobacco epidemic.

Key word: tobacco epidemic, pharmacotherapy methods. 